\title{
Spectroscopic Evaluation of Novel Tacrine- Coumarin Hybrids as HSA-Interacting Agents
}

\author{
Eva Konkol'ová ${ }^{1}$, Monika Hudačová ${ }^{1}$, Slávka Hamulaková2 ${ }^{2}$, Mária Kožurková ${ }^{1,3 *}$ \\ ${ }^{1}$ Department of Biochemistry, Faculty of Science, PJ Šafárik University, Slovak Republic \\ ${ }^{2}$ Department of Organic Chemistry, Faculty of Science, PJ Šafárik University, Slovak Republic \\ ${ }^{3}$ Biomedical Research Center, University Hospital Hradec Kralove, Hradec Kralove, Czech Republic
}

Submission: January 16, 2019 Published: February 27, 2019

"Corresponding author: Maria Kozurkova, Department of Biochemistry, Institute of Chemistry, Faculty of Science, P J Šafárik University in Košice, Slovak Republic

\begin{abstract}
In this work, we investigated the human serum albumin binding behavior of a series of novel derivatives with both tacrine and coumarin pharmacophores. The compounds were investigated using UV-Vis absorption and fluorescence spectroscopy. KB values were found to be in order of $10^{3} \mathrm{M}^{-1}$. The values of $\mathrm{n}$ indicate that only one independent class of binding sites is available for tacrine-coumarin hybrids on HSA. Synchronous fluorescence spectra showed that compounds did not have any noticeably effect on $\alpha$-helical conformation of HSA. Our data indicated that these tacrine-coumarin molecules exhibit promising potential which would be of considerable use in the development of drugs with enhanced or more selective effects and greater clinical efficacy.
\end{abstract}

Keywords: Tacrine-coumarin hybrid molecules; Human serum albumin; Spectroscopic techniques; Synchronous fluorescence studies

\section{Introduction}

Coumarins (benzopyran-2-ones) form an elite class of naturally occurring compounds which possess a wide range of promising therapeutic perspectives. Due to the diversity of their structural complexity, these compounds can range from simple substituted coumarins to polysubstituted polycyclic/fused coumarins. They belong to the flavonoid class of plant secondary metabolites and exhibit a variety of biological activities while also typically displaying low levels of toxicity. Both natural and synthetic coumarins have attracted a great deal of attention due to the wide range of their biological properties, which include anticancer, anti-HIV, anti-inflammatory and antibacterial activities [1-13]. Recent research has also focussed attention on the human serum albumin (HSA) [14,15].

Serum albumins are the most common proteins in the circulatory system and these biomacromolecules play a crucial role in the transport of ions, drug and metal ions through the bloodstream to biological targets such as cells and tissues. They are also involved in the many exogenous and endogenous components such as fatty acids or pharmaceuticals. When we take into consideration the fact that the biological properties of compounds may be changed or adopt alternative transportation pathways or mechanisms when bound to albumins, it is clear that an investigation of the interaction of potential biologically active compounds with albumins could provide important information about the potential biological activity of such compounds $[16,17]$. The intrinsic fluorescence of human serum albumin is caused by three distinct agents; tryptophan (Trp), tyrosine (Tyr) and phenylalanine (Phe). However, Phe has a very low quantum yield and the fluorescence of Tyr is almost totally quenched if it is ionized or in close proximity to an amino group, a carboxyl group or a Trp residue, so therefore the main agent responsible for the fluorescence of HSA is tryptophan (Trp) [1819]. The fluorescence intensity of HSA may be quenched by a variety of molecular interactions, such as excited state reactions, energy transfer, molecular rearrangement, the formation of a non-fluorescent ground state complex (static quenching) and collisional encounters between fluorophores and quenchers (dynamic quenching) [20-21].

A further factor is the inner filter effect which is connected to the absorption of light at the excitation or emission wavelength by compounds present in the solution. When compounds added to a solution absorb high levels of light at the excitation or emission wavelength of proteins, it is possible that less light will penetrate to the centre of the solution or that less emitted light 
will reach the detector. Either of these situations can lead to a reduction in the fluorescence intensity of proteins and result in inner filter effect-induced fluorescence quenching [20-22]. In this study we investigate the interaction of four drugs possessing both tacrine and coumarin pharmacophores with human serum albumin.

Table 1: Characteristics of compounds 1a-1d.

\begin{tabular}{|c|c|c|}
\hline \multirow{2}{*}{ Compound } & \multirow{2}{*}{ Name } & Molecular weight \\
\hline & & (g mol-1) \\
\hline $1 \mathrm{a}$ & N1-\{6-[(1,2,3,4-tetrahydroacridin-9-yl) amino hexyl\}-2-(7-hydroxy-2-oxo-2H-chromen-4-yl) acetamide & 499.62 \\
\hline $1 \mathrm{~b}$ & N1-\{7-[(1,2,3,4-tetrahydroacridin-9-yl) amino] heptyl\}-2-(7-hydroxy-2-oxo-2H-chromen-4-yl) acetamide & 513.64 \\
\hline $1 \mathrm{c}$ & N1-\{8-[(1,2,3,4-tetrahydroacridin-9-yl) amino] octyl\}-2-(7-hydroxy-2-oxo-2H-chromen-4-yl) acetamide & 527.67 \\
\hline $1 \mathrm{~d}$ & N1-\{9-[(1,2,3,4-tetrahydroacridin-9-yl) amino] nonyl\}-2-(7-hydroxy-2-oxo-2H-chromen-4-yl) acetamide & 541.7 \\
\hline
\end{tabular}

\section{Experimental}

\section{Chemistry}

All chemicals and reagents were purchased from SigmaAldrich Chemie (Germany) and used without further purification. The studied tacrine-coumarin hybrids were prepared at the Institute of Chemistry, Department of Organic chemistry, Faculty of Science, PJ Šafárik University in Košice. A description of the synthesis and their biological activity of these compounds has been published previously [23]. The hybrids were dissolved in dimethyl sulfoxide (DMSO, Fluka) to a final concentration $5 \times 10^{-2}$ M. The chemical characteristics are listed in (Table 1).

Human serum albumin sample preparation: Fatty-acid free human serum albumin (HSA, A1887, Sigma Aldrich) was prepared by dissolving $40 \times 10^{-3} \mathrm{~g} / \mathrm{mL}$ in a $10 \times 10^{-3} \mathrm{M}$ Tris- $\mathrm{HCl}$ buffer ( $\mathrm{pH}$ 7.4) containing $0.1 \mathrm{M} \mathrm{NaCl}$. The final concentration of HSA stock solution was determined spectrophotometrically using a molar absorption coefficient of $\varepsilon_{280}=35700 \mathrm{M}^{-1} \mathrm{~cm}^{-1}$ [24]. Fluorescence measurements: Fluorescence measurements were performed at three different temperatures (288.15, 298.15 and $310.15 \mathrm{~K}$ ) on the fluorescence spectrophotometer equipped with a $1.0 \mathrm{~cm}$ quartz cuvette which was mentioned above. The excitation and emission slit widths were set at $10 \mathrm{~nm}$. Fluorescence quenching spectra were obtained by excitation at $295 \mathrm{~nm}$ in the wavelength range of $305-500 \mathrm{~nm}$. Spectra were measured at fixed concentrations of HSA $\left(c=4.0 \times 10^{-6} \mathrm{M}\right)$ and increasing concentrations of compounds $1 \mathrm{a}-1 \mathrm{~d}$. The fluorescence emission spectra of the free studied compounds were also obtained under the same experimental conditions and displayed a maximum emission band at $\sim 450 \mathrm{~nm}$. Quenching studies of the HSA fluorescence spectra were performed after correlation by subtracting the spectra of the free compounds $[16,17]$. Fluorescence intensities were corrected in order to eliminate the inner filter effect and all fluorescence intensities used in the protein binding studies were corrected values.

UV-Vis absorption experiments: Absorption spectra were performed at three different temperatures (288.15, 298.15 and $310.15 \mathrm{~K}$ ) on the spectrophotometer set-up which was described above. Spectra were measured at fixed concentrations of HSA (c $=4.0 \times 10^{-6} \mathrm{M}$ ) and increasing concentrations of compounds $1 \mathrm{a}-$ $1 \mathrm{~d}$. Baseline correlation was performed using the corresponding buffer (Tris-HCl-NaCl). Synchronous fluorescence spectroscopic studies: Synchronous fluorescence spectra were recorded at different scanning intervals of $\Delta \lambda$. The relationship of the synchronous emission and excitation wavelengths can be expressed as $\Delta \lambda=\lambda \mathrm{em}-\lambda$ ex. The excitation wavelength was set in the range of $240-360 \mathrm{~nm}$ and the emission were recorded at $\Delta$ $=15 \mathrm{~nm}$ for tyrosine (Tyr) residues and $\Delta=60 \mathrm{~nm}$ for tryptophan (Trp) residues. Spectra were measured at fixed concentrations of HSA $\left(c=4.0 \times 10^{-6} \mathrm{M}\right)$ and increasing concentrations of compounds $1 \mathrm{a}-1 \mathrm{~d}$.

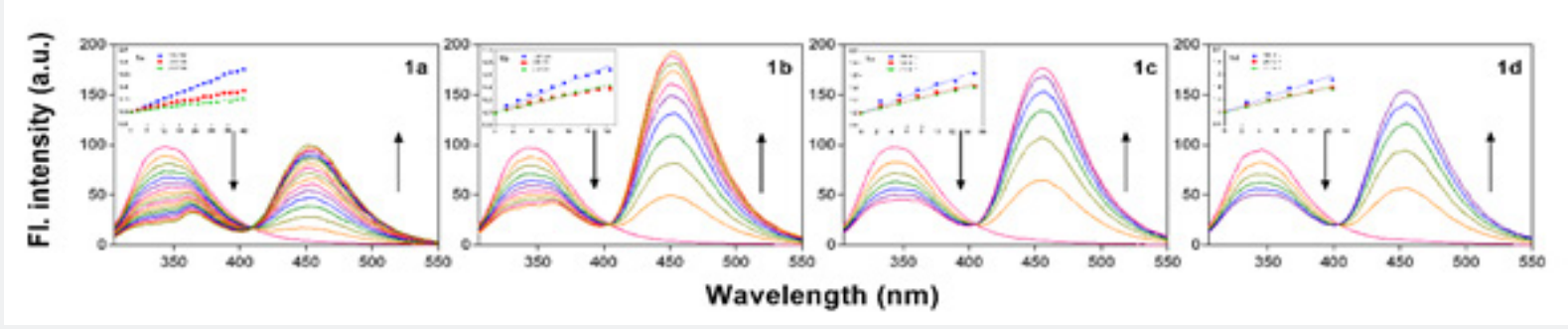

Figure 1: Fluorescence spectra of $4.0 \times 10^{-6} \mathrm{M} \mathrm{HSA}(\lambda \mathrm{ex}=295 \mathrm{~nm} ; \lambda \mathrm{em}=345 \mathrm{~nm})$ in the presence of compound $1 \mathrm{a}-1 \mathrm{~d}$ at $25^{\circ} \mathrm{C}([1 \mathrm{a}]=0-4.2 \times$ $\left.10^{-5} \mathrm{M},[1 \mathrm{~b}]=0-2.5 \times 10^{-5} \mathrm{M},[1 \mathrm{c}]=0-1.5 \times 10^{-5} \mathrm{M},[1 \mathrm{~d}]=0-1.2 \times 10^{-5} \mathrm{M}\right)$. Arrows indicate changes in fluorescence spectra upon increasing the ligand concentration. Insert: The Stern-Volmer plot of fluorescence quenching of HSA by studied compounds at $25^{\circ} \mathrm{C}$. All the experiments were realized in Tris- $\mathrm{HCl}-\mathrm{NaCl}$ buffer, $\mathrm{pH} 7.4$. 


\section{Results and Discussion}

\section{Fluorescence Quenching Measurements}

In order to investigate the interaction of compounds 1a-1dwith HSA, Trp fluorescence emission quenching experiments were performed at three different temperatures (289.15, 298.15 and $310.15 \mathrm{~K}$ ) (Figure 1). When the solution of HSA is excited at $295 \mathrm{~nm}$, the emission spectra exhibit the intensive band at $343 \mathrm{~nm}$. This band originates from Trp at position 214 in HSA. The fluorescence intensity of HSA was found to decrease gradually upon successive additions of compounds 1a-1d. Moreover, another emission band appeared at $450 \mathrm{~nm}$ at increased concentrations of the compounds, an effect which is characteristic for tacrine-coumarin hybrids, and this was followed by the development of an isoemission point at $410 \mathrm{~nm}$. The influence of the inner filter effect on the fluorescence of HSA quenched by compounds $1 \mathrm{a}-1 \mathrm{~d}$ was estimated prior to the analysis of the fluorescence quenching mechanism using by the following (Equation 1) $[25]$

$$
F_{c o r}=F_{o b s} x e \frac{A e x=A e m}{2}
$$

where Fcor and Fobs are the fluorescence intensities correlated and observed, respectively; Aex and Aem are the absorbance values of the studied compounds at the excitation and emission wavelengths, respectively. Both static and dynamic processes were then defined, and quenching data was analysed using the classical linear Stern-Volmer (Equation 2) as follows [26]

$$
\frac{F_{o}}{F}=1+k_{q} \operatorname{tau}[Q]=1+K_{s v}[Q]
$$

where $\mathrm{F}_{0}$ and $\mathrm{F}$ are the fluorescence intensities of HSA (fluorophore) in the absence and presence of the compounds (quencher), respectively; [Q] is the concentration of the ligand; $\mathrm{KSV}$ is the Stern-Volmer quenching constant; kq is the bimolecular quenching rate constant and $\tau_{0}$ is the average lifetime of the fluorophore in the absence of ligands (typically with a value of $1 \times 10-8$ for Trp fluorescence in protein molecules).

Figure 1 show the linear plot of $F_{0} / F$ versus [Q]. The linear course of the Stern-Volmer plot represents a single quenching mechanism, either dynamic or static [27]. The values of the SternVolmer quenching constants $\mathrm{K}_{\mathrm{SV}}$ were evaluated from the slopes of the linear plots, and the bimolecular quenching constants $\mathrm{kq}$ were then calculated by applying (Equation 2); all of the related data is listed in (Table 2). Dynamic and static quenching can be distinguished by their temperature-dependent behaviour. The stability of the HSA-compound complex is typically reduced at increased temperatures and thus static quenching is characterized by a decreasing bimolecular quenching constant at increased temperatures.

\begin{tabular}{|c|c|c|c|c|c|c|c|c|c|c|}
\hline \multirow[b]{2}{*}{ Comp } & \multirow[b]{2}{*}{$\mathbf{T}(\mathrm{K})$} & $\mathbf{K}_{\mathrm{sv}}$ & $\mathbf{k}_{\mathrm{q}}$ & $K_{B}$ & \multirow[b]{2}{*}{$\mathbf{n}$} & \multirow[b]{2}{*}{$\mathbf{R}^{2}$} & $\Delta \mathbf{G}$ & $\Delta \mathbf{H}$ & $\Delta \mathrm{S}$ & \multirow[b]{2}{*}{$\mathbf{R}^{2}$} \\
\hline & & $\mathbf{s}$ & $\begin{array}{l}\left(\times 10^{11}\right. \\
\left.M^{-1} s^{-1}\right)\end{array}$ & $\left(\times 10^{3} M^{-1}\right)$ & & & $\left(\mathrm{kJ} \mathrm{mol}^{-1}\right)$ & $\left(\mathrm{kJ} \mathrm{mol}^{-1}\right)$ & $\begin{array}{c}\left(\mathrm{J} \mathrm{mol}^{-1}\right. \\
\left.\mathrm{K}^{-1}\right)\end{array}$ & \\
\hline \multirow{3}{*}{$1 \mathrm{a}$} & 288.15 & 16.81 & 16.81 & 15.86 & 0.99 & 1 & -22.39 & \multirow{3}{*}{-115.12} & \multirow{3}{*}{-321.81} & \multirow{3}{*}{0.91} \\
\hline & 298.15 & 8.58 & 8.58 & 1.23 & 0.81 & 1 & -19.17 & & & \\
\hline & 310.15 & 5.4 & 5.4 & 0.51 & 0.77 & 0.98 & -15.31 & & & \\
\hline \multirow{3}{*}{$1 b$} & 288.15 & 30.55 & 30.55 & 3.32 & 0.8 & 1 & -19.54 & \multirow{3}{*}{53.9} & \multirow{3}{*}{254.87} & \multirow{3}{*}{0.99} \\
\hline & 298.15 & 17.16 & 17.16 & 8.06 & 0.93 & 0.99 & -22.08 & & & \\
\hline & 310.15 & 18.5 & 18.5 & 16.44 & 0.99 & 1 & -25.14 & & & \\
\hline \multirow{3}{*}{$1 c$} & 288.15 & 44.65 & 44.65 & 0.86 & 0.65 & 0.99 & -15.79 & \multirow{3}{*}{68.81} & \multirow{3}{*}{293.56} & \multirow{3}{*}{0.94} \\
\hline & 298.15 & 31.85 & 31.85 & 1.76 & 0.75 & 1 & -18.72 & & & \\
\hline & 310.15 & 29.34 & 29.34 & 6.45 & 0.87 & 1 & -22.24 & & & \\
\hline \multirow{3}{*}{$1 d$} & 288.15 & 47.21 & 47.21 & 2.58 & 0.75 & 0.99 & -18.36 & \multirow{3}{*}{65.1} & \multirow{3}{*}{289.66} & \multirow{3}{*}{0.91} \\
\hline & 298.15 & 33.45 & 33.45 & 3.69 & 0.81 & 0.99 & -21.26 & & & \\
\hline & 310.15 & 32.49 & 32.49 & 17.38 & 0.94 & 0.98 & -24.74 & & & \\
\hline
\end{tabular}

Table 2: Various binding and thermodynamic parameters for compound-HSA complex formation at various temperatures.

In contrast, dynamic quenching occurs when higher temperatures increase the bimolecular quenching constant as a result of faster diffusion and greater likelihood of collision at the highest temperatures $[25,28]$. The $\mathrm{kq}$ values obtained in this study are 100 -fold higher than the maximum scatter collisional quenching constant, which is given as $2.0 \times 10^{10} \mathrm{M}^{-1} \mathrm{~S}^{-1}$ [26] and $\mathrm{kq}$ values decrease with increases in temperature. This data suggests that compounds $1 \mathrm{a}-1 \mathrm{~d}$ can quench the fluorescence of proteins' Trp residues as a result of ground-state complex forma- tion with HSA (static quenching). Furthermore, slight red shifts $(343 \mathrm{~nm} \rightarrow 345 \mathrm{~nm})$ were observed in the position of the emission maximum upon addition of the studied compounds. These shifts are probably related to a change in the microenvironmental polarity surrounding the Trp residues in HSA molecules. The red shift is likely to be a result of disruption to the structure of HSA brought about by the formation of the compound complex. When the compounds bind to HSA, the Trp residues buried in the hydrophobic cavity are exposed to water, an environment which is 
more polar but less hydrophobic [29]. Accordingly, similar shifts were also observed using other methods such as synchronous spectra and absorption spectra, the results of which are listed below.

\section{Binding Constant, Number of Binding Sites and Ther- modynamic Parameters}

The binding constant (KB) and the number of binding sites (n) of compounds 1a-1 dbound to HSA at different temperatures were determined by plotting the double logarithmic regression curve of the fluorescence data using the above-mention (Equation 3) [25].

$$
\log \frac{F_{o}-F}{F}=n \log [Q]=\log K_{B}
$$

The values of $\mathrm{KB}$ and $\mathrm{n}$ were collected from linear plots of $\log \left[\left(\mathrm{F}_{0}-\mathrm{F}\right) / \mathrm{F}\right]$ versus $\log [\mathrm{Q}]$ as shown in figure 2 and the corresponding values are presented in Table 2. As can be seen in the table, the $\mathrm{KB}$ values of these compounds at the same temperature decrease in the order $1 b>1 d>1 c>1 a$. These findings show that the length of the chain between tacrine and coumarin has an effect on binding strength because compounds with even numbers of $-\mathrm{CH}_{2}$ groups displayed lower binding affinity than compounds with odd numbers of $-\mathrm{CH}_{2}$ groups. However, the $\mathrm{KB}$ values were found to be in order of $10^{3} \mathrm{M}^{-1}$ which suggests that the affinity of interaction between the compounds and HSA is weaker than the optimal range of affinity of $10^{4}-10^{6} \mathrm{M}^{-1}$ necessary for the transportation and distribution of compounds through the organism. In terms of binding sites, the values of $\mathrm{n}$ obtained in the assays were approximately equal to 1 which indicates that only one independent class of binding sites is available for tacrine-coumarin hybrids on HSA [30] (Figure 2).

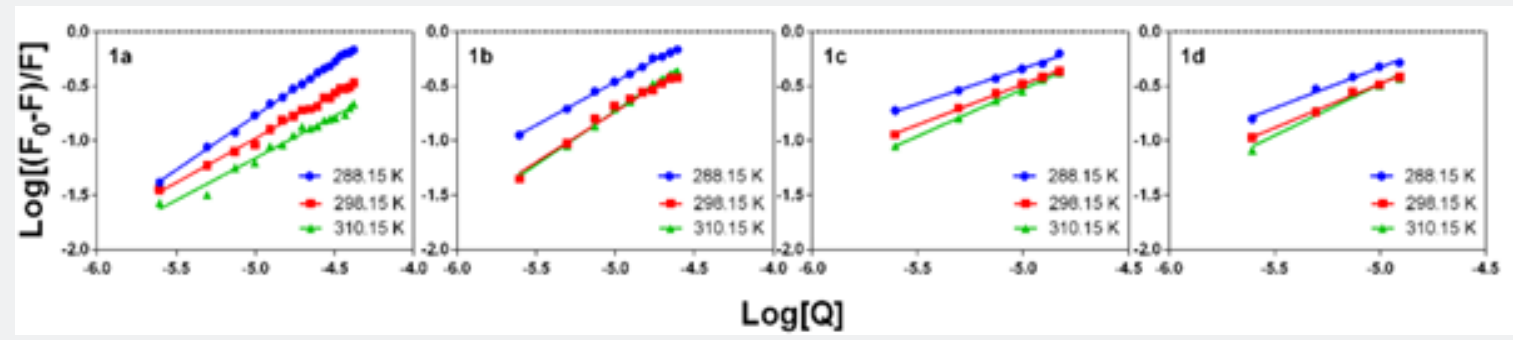

Figure 2: Logarithmic plot of the fluorescence quenching of HSA with tacrine-coumarin derivatives 1a-1d at various temperature.

The thermodynamic parameters of binding of compounds 1a1d with HSA were determined using a Van't Hoff plot figure 3 was used to calculate the changes in both enthalpy $(\Delta \mathrm{H})$ and entropy
$(\Delta S)$. The changes in Gibbs free energy $(\Delta G)$ were determined as a function of temperature [30]. The calculated results are also presented in (Table 2) (Figure 3).

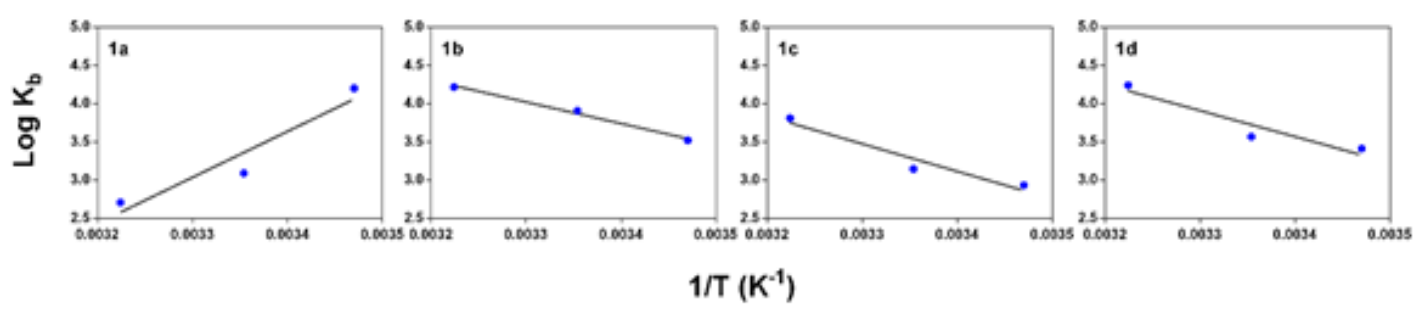

Figure 3: Van't Hoff plot for the interaction of HSA with tacrine-coumarin derivatives obtained from HSA fluorescence quenching at 288.15 , 298.15 and $310.15 \mathrm{~K}$.

As was mentioned above, when $\Delta \mathrm{H}$ and $\Delta \mathrm{S}$ are both negative, the main forces in the interaction are van der Waals forces and hydrogen bonding; when $\Delta \mathrm{H}$ and $\Delta \mathrm{S}$ are both positive, hydrophobic interaction is the main force, but when $\Delta \mathrm{H}$ is zero or slightly negative and $\Delta \mathrm{S}$ is positive, electrostatic interaction plays a major role in the reactions [28-31]. Moreover, when the binding enthalpy is positive, the binding process has an endothermic character which can be indicated by a boost to KB values as a function of temperature raise. However, when $\Delta \mathrm{H}$ is negative, the binding process is exothermic, and the values of $\mathrm{KB}$ decrease with increasing temperature [28]. The negative values of $\Delta \mathrm{G}$ (Table 2) indicate that the binding of tacrine-coumarin hybrids $1 \mathrm{a}-1 \mathrm{~d}$ to HSA is a spontaneous process. In addition, the positive values of $\Delta \mathrm{H}$ and $\Delta \mathrm{S}$ indicate that the binding interaction between compounds $1 \mathrm{~b}-1 \mathrm{~d}$ and HSA is primarily an entropydriven endothermic reaction in which hydrophobic forces play a major role. Interestingly, the interaction between HSA and compound 1a clearly suggests the occurrence of a different binding mode because the values of $\Delta \mathrm{H}$ and $\Delta \mathrm{S}$ are both negative and therefore the main forces are probably van der Waal forces and hydrogen bonding.

\section{UV-Vis Absorption Spectroscopy}

UV-Vis spectroscopy is a simple and useful method of investigating structural and microenvironmental changes in protein-compound complex formation. The absorption spectrum 
of HSA exhibits a stronger absorption band at $210 \mathrm{~nm}$ which reflects the framework conformation of the protein, while a weaker absorption band at $279 \mathrm{~nm}$ is attributed to the aromatic amino acids (Trp, Tyr, Phe) present in the protein [32]. As is shown in Figure 4, the absorption bands at $210 \mathrm{~nm}$ and $279 \mathrm{~nm}$ displayed a gradual increase in the presence of compounds $1 \mathrm{a}-$ 1d. Additional bands were also observed at $335 \mathrm{~nm}$.

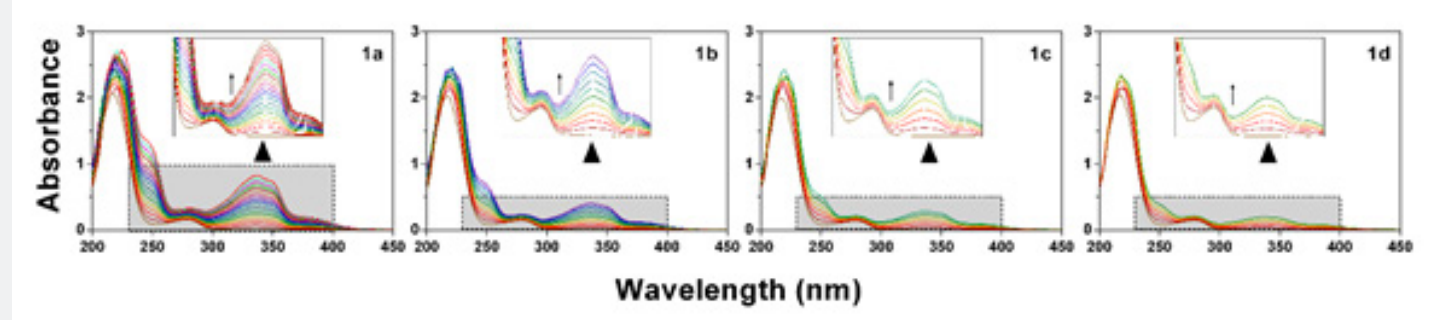

Figure 4: Absorption spectra of $4.0 \times 10^{-6} \mathrm{M}$ HSA gradually titrated with compounds $1 \mathrm{a}-1 \mathrm{~d}\left([1 \mathrm{a}]=0-4.2 \times 10^{-5} \mathrm{M},[1 \mathrm{~b}]=0-2.5 \times 10^{-5} \mathrm{M},[1 \mathrm{c}]=\right.$ $0-1.5 \times 10^{-5} \mathrm{M},[1 \mathrm{~d}]=0-1.2 \times 10^{-5} \mathrm{M}$ ) at $25^{\circ} \mathrm{C}$ in Tris- $\mathrm{HCl}-\mathrm{NaCl}$ buffer, $\mathrm{pH}$ 7.4. Arrows indicate changes in absorption spectra upon increasing the ligand concentration.

These bands are characteristic of the absorption maxima of free compounds and their intensity increased with increasing concentrations of the studied compounds. The increase in the characteristic HSA peaks at $210 \mathrm{~nm}$ and $279 \mathrm{~nm}$ in addition to the slight red shifting of the maximum wavelength of HSA $(\sim 2 \mathrm{~nm})$ indicate that the structure of HSA was changed and the hydrophobicity of the microenvironment around the aromatic residues was decreased in the presence of compounds $1 \mathrm{a}-1 \mathrm{~d}$.

\section{Synchronous Fluorescence Spectroscopic Studies}

Synchronous fluorescence spectroscopy is a frequently used method which can provide valuable information about conformation changes of proteins and alterations of polarity, especially in the microenvironment of amino acid residues. When $\Delta \lambda$ values (scanning interval, $\Delta \lambda=\lambda$ em- $\lambda$ ex) are set at $15 \mathrm{~nm}$ $(\Delta \lambda=15 \mathrm{~nm})$, the synchronous spectrum provides characteristic information about the tyrosine residue, while at $\Delta \lambda=60 \mathrm{~nm}$, the spectrum offers details about the tryptophan residue [29,33]. The maximum emission wavelength shift $\left(\lambda_{\max }\right)$ can indicate a modification of the polarity in the surrounding fluorophores. When a blue shift in $\lambda_{\max }$ is observed, the polarity around the fluorophores has decreased and the hydrophobicity has increased. Conversely, when a red shift in $\lambda \max$ is observed, the polarity around the fluorophores has increased, while the hydrophobicity has decreased $[14,34,35]$.

The synchronous fluorescence spectra of compounds 1a$1 \mathrm{~d}$ with HSA at $\Delta \lambda=15 \mathrm{~nm}$ and $\Delta \lambda=60 \mathrm{~nm}$ are shown in Figure 5. A slight red shift was observed in the spectra of Tyr and Trp residues $(\sim 2 \mathrm{~nm})$ which indicates that the microenvironment around the Trp and Tyr residues was disrupted; more specifically, the hydrophobicity of Trp and Tyr residues had decreased and the polarity around these residues had increased. Moreover, fluorescence intensity was found to decrease regularly upon the addition of compounds $1 \mathrm{a}-1 \mathrm{~d}$. This is likely to be a result of fluorescence quenching and corroborates the findings obtained from the fluorescence quenching assays.

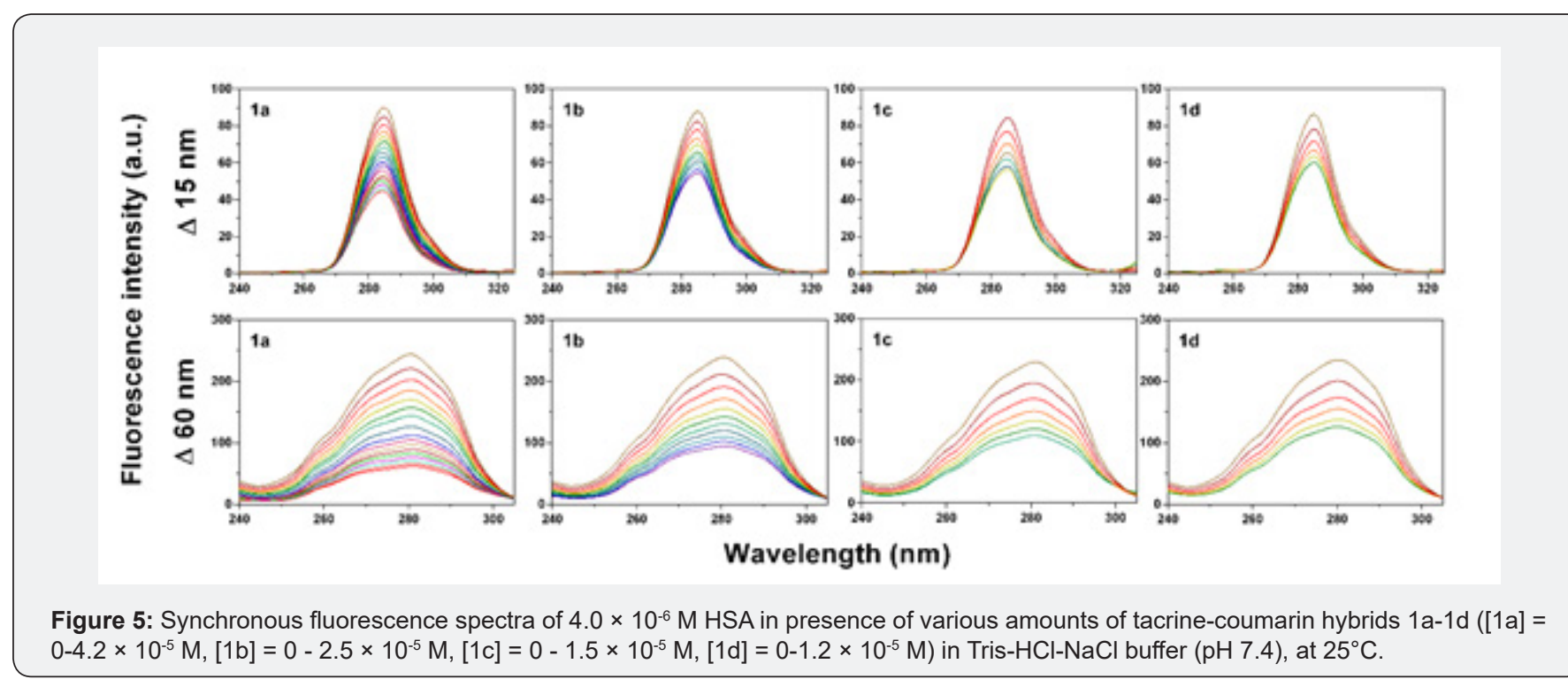




\section{Conclusion}

The HSA binding behavior of a series of novel derivatives with both tacrine and coumarin pharmacophores, compounds $1 \mathrm{a}-1 \mathrm{~d}$, was investigated with HSA using UV-Vis absorption and fluorescence spectroscopy. The results obtained from the fluorescence spectrometry allowed us to calculate $\mathrm{KB}$ value. KB values were found to be in order of $10^{3} \mathrm{M}^{-1}$ which suggests that the affinity of interaction between the compounds and HSA is weaker than the optimal range of affinity of $10^{4}-10^{6} \mathrm{M}^{-1}$ necessary for the transportation and distribution of compounds through the organism. The values of $\mathrm{n}$ indicate that only one independent class of binding sites is available for tacrine-coumarin hybrids on HSA. Synchronous fluorescence spectra showed that compounds did not have any noticeably effect on $\alpha$-helical conformation of HSA. The findings presented in this paper offer significant insights into the interaction between the novel tacrine-coumarin compounds and human serum albumin. Our data suggests that these tacrine-coumarin molecules exhibit promising potential which would be of considerable use in the development of drugs with enhanced or more selective effects and greater clinical efficacy.

\section{Acknowledgement}

The present work was supported by Grant Program of P J Šafárik University in Košice VEGA 1/0016/18 and MH CZ - DRO (UHHK, 00179906).

\section{References}

1. Kashman Y, Gustafson KR, Fuller RW, Cardellina JH, McMahon JB, et al. (1992) HIV inhibitory natural products. Part 7. The calanolides, a novel HIV-inhibitory class of coumarin derivatives from the tropical rainforest tree, Calophyllum lanigerum. J Med Chem 35(15): 27352743.

2. Gormley NA, Orphanides G, Meyer A, Cullis PM, Maxwell A (1996) The interaction of coumarin antibiotics with fragments of the DNA gyrase $B$ protein. Biochemistry 35(15): 5083-5092.

3. Shikishima Y, Takaishi Y, Honda G, Ito M, Takeda Y, et al. (2001) Chemical constituents of prangos tschimganica; structure elucidation and absolute configuration of coumarin and furanocoumarin derivatives with anti-HIV activity. Chem Pharm Bull 49(7): 877-880.

4. Madhavan G, Balraju V, Mallesham B, Chakrabarti R, Lohray VB (2003) Novel coumarin derivatives of heterocyclic compounds as lipidLowering agents. Bioorg Med Chem Lett 13(15): 2547-2551.

5. Konstantina CF, Dimitra JH-L, Konstantinos EL, Demetrios NN (2004) Natural and synthetic coumarin derivatives with anti-Inflammatory/ antioxidant activities. Curr Pharm Des 10(30): 3813-3833.

6. Curini M, Cravotto G, Epifano F, Giannone G (2006) Chemistry and biological activity of natural and synthetic prenyloxycoumarins. Curr Med Chem 13(2): 199-222.

7. Ostrov DA, Hernández Prada JA, Corsino PE, Finton KA, Le N, Rowe TC (2007) Discovery of novel DNA gyrase inhibitors by high-throughput virtual screening. Antimicrob Agents Chemother 51(10): 3688-3698.

8. Piazzi L, Cavalli A, Colizzi F, Belluti F, Bartolini M, et al. (2008) Multitarget-directed coumarin derivatives: hAChE and BACE1 inhibitors as potential anti-Alzheimer compounds. Bioorg Med Chem Lett 18(1): 423-426.

9. Yuce B, Danis O, Ogan A, Sener G, Bulut M, et al. (2009) Antioxidative and lipid lowering effects of 7,8-dihydroxy-3-(4-methylphenyl) coumarin in hyperlipidemic rats. Arzneimittel-Forschung 59(3): 129-34.

10. Yeh JY, Coumar MS, Horng JT, Shiao HY, Kuo FM, et al. (2010) AntiInfluenza Drug Discovery: Structure-activity relationship and mechanistic insight into novel angelicin serivatives. J Med Chem 53(4): 1519-1533.

11. Manvar A, Bavishi A, Radadiya A, Patel J, Vora V, Dodia N, Rawal K, Shah A et al. (2011) Diversity oriented design of various hydrazides and their in vitro evaluation against Mycobacterium tuberculosis H37Rv strains. Bioorg Med Chem Lett 21(16): 4728-4731.

12. Anand P, Singh B, Singh N (2012) A review on coumarins as acetylcholinesterase inhibitors for Alzheimer's disease. Bioorg Med Chem Lett 20(3): 1175-1180.

13. Bansal Y, Sethi P, Bansal G (2013) Coumarin: a potential nucleus for anti-inflammatory molecules. Med Chem Res 22(7): 3049-3060.

14. Konkolová E, Janočková J, Perjési P, Vašková J, Kožurková M (2018) Selected ferrocenyl chalcones as DNA/BSA-interacting agents and inhibitors of DNA topoisomerase I and II activity. J Organomet Chem 861: 1-9.

15. Andrezalova L, Plsikova J, Janockova J, Konarikova K, Zitnanova I, et al. (2017) DNA/BSA binding ability and genotoxic effect of mono- and binuclear copper (II) cpmlexes containing a Shiff base derived from salicylaldehyde and L,L-glutamic acid. J Organomet Chem 827: 67-77.

16. Kostelidou A, Kalogiannis S, Begou OA, Perdih F, Turel I, et al. (2016) Synthesis, structure and biological activity of copper(II) complexes with gatifloxacin. Polyhedron 119: 359-370.

17. Tarushi, A, Kakoulidou C, Raptopoulou CP, Psycharis V, Kessissoglou DP, $\mathrm{t}$ al. (2017) Zinc complexes of diflunisal: Synthesis, characterization, structure, antioxidant activity, and in vitro and in silico study of the interaction with DNA and albumins. J Inorg Biochem 170: 85-97.

18. Ariga GG, Naik PN, Chimatadar SA, Nandibewoor ST (2017) Interactions between epinastine and human serum albumin: Investigation by fluorescence, UV-vis, FT-IR, CD, lifetime measurement and molecular docking. J Mol Struct 1137: 485-494.

19. Zhang G, Zhao N, Wang L (2011) Fluorescence spectrometric studies on the binding of puerarin to human serum albumin using warfarin, ibuprofen and digitoxin as site markers with the aid of chemometrics. J Lumin 131(12): 2716-2724.

20. Makarska BM (2017) Investigation of the binding affinity in vitamin B12-Bovine serum albumin system using various spectroscopic methods. Spectrochim Acta A Mol Biomol Spectrosc 184: 262-269.

21. Mohammadi F, Bordbar AK, Divsalar A, Mohammadi K, Saboury AA (2009) Analysis of Binding Interaction of Curcumin and Diacetylcurcumin with Human and Bovine Serum Albumin Using Fluorescence and Circular Dichroism Spectroscopy. Protein J 28(3-4): 189-196.

22. Stella L, Capodilupo AL, Bietti M (2008) A reassessment of the association between azulene and [60]fullerene. Possible pitfalls in the determination of binding constants through fluorescence spectroscopy. Chem Commun 39: 4744-4746.

23. Hamulakova S, Poprac P, Jomova K, Brezova V, Lauro P, et al. (2016) Targeting copper(II)-induced oxidative stress and the acetylcholinesterase system in Alzheimer's disease using multifunctional tacrine-coumarin hybrid molecules. J Inorg Biochem 161: 52-62. 
24. Wang Q Zhang Y, LiH (2017) Octyl gallate: An antioxidant demonstrating selective and sensitive fluorescent property. Food Chem 219: 268-273.

25. Tang P, Tang B, Wang Q Xu K, Xiong X, et al. (2016) Effect of hydroxypropyl- $\beta$-cyclodextrin on the bounding of salazosulfapyridine to human serum albumin. Int J Biol Macromol. 92: 105-115.

26. Lakowicz JR (2006) Principles of fluorescence spectroscopy, ( $3^{\text {rd }}$ edn) Springer, New York.

27. Shokohi PZ, Chiniforoshan H, Momtazi BAA, Notash B (2016) A novel Schiff base derived from the gabapentin drug and copper (II) complex: Synthesis, characterization, interaction with DNA/protein and cytotoxic activity. J Photoch Photobio B 162: 34-44.

28. Shahsavani MB, Ahmadi S, Aseman MD, Nabavizadeh SM, Alavianmehr $\mathrm{MM}$, et al. (2016) Comparative study on the interaction of two binuclear Pt (II) complexes with human serum albumin: Spectroscopic and docking simulation assessments. J Photochem Photobiol B, Biol 164: 323-334.

29. Tang J, Luan F, Chen X (2006) Binding analysis of glycyrrhetinic acid to human serum albumin: Fluorescence spectroscopy, FTIR, and molecular modeling. Bioorg Med Chem Lett. 14(9): 3210-3217.
30. Topala T, Bodoki A, Oprean L, Oprean R (2014) Bovine Serum Albumin Interactions with Metal Complexes. Clujul medical 87(4): 215-219.

31. Ross PD, Subramanian S (1981) Thermodynamics of protein association reactions: forces contributing to stability. Biochemistry 20(11): 3096-3102.

32. Nithya P, Helena S, Simpson J, Ilanchelian M, Muthusankar A, et al. (2016) New cobalt(II) and nickel(II) complexes of benzyl carbazate Schiff bases: Syntheses, crystal structures, in vitro DNA and HSA binding studies. J Photochem Photobiol B, Biol 165: 220-231.

33. Miller JN (1979) Recent advances in molecular luminescence analysis. Proc Anal Div Chem Soc 16: 203-208.

34. Li C, Huang T, Fu Y, Liu Y, Zhou S, et al. (2016) Interaction of di-2pyridylketone 2-pyridine carboxylic acid hydrazone and its copper complex with BSA: effect on antitumor activity as revealed by spectroscopic studies. Molecules 21(5): 563.

35. Hao C, Xu G, Feng Y, Lu L, Sun W, Sun Ret al. (2017) Fluorescence quenching study on the interaction of ferroferric oxide nanoparticles with bovine serum albumin. Spectrochim Acta A Mol Biomol Spectrosc 184: 191-197.

\section{Your next submission with Juniper Publishers} will reach you the below assets

- Quality Editorial service

- Swift Peer Review

- Reprints availability

- E-prints Service

- Manuscript Podcast for convenient understanding

- Global attainment for your research

- Manuscript accessibility in different formats ( Pdf, E-pub, Full Text, Audio)

- Unceasing customer service

Track the below URL for one-step submission https://juniperpublishers.com/online-submission.php 